\title{
Testing Phase-Specific Self-Efficacy Beliefs in the Context of Dietary Behaviour Change
}

\author{
Sibylle Ochsner* \\ University of Zurich, Switzerland \\ Urte Scholz \\ University of Konstanz, Germany \\ Rainer Hornung \\ University of Zurich, Switzerland
}

\begin{abstract}
Background: Self-efficacy is an important predictor of health behaviour change. Within the health action process approach (HAPA; Schwarzer, 2008), motivational and volitional self-efficacy can be distinguished. Motivational selfefficacy is assumed to serve as predictor of intention formation whereas volitional self-efficacy should be relevant for behaviour change. This study examined these assumptions in a sample with overweight and obese individuals. Moreover, we tested whether behavioural intentions moderate the association between volitional self-efficacy and behaviour. Methods: Overall, 373 overweight and obese individuals completed a baseline and six months later a follow-up questionnaire on HAPA variables and dietary behaviour. Results: A factor analysis confirmed the phase-specific separation of self-efficacy. Motivational self-efficacy emerged as predictor for behavioural intentions over and above other HAPA variables after six months, whereas volitional self-efficacy did not. Volitional self-efficacy interacted with intention in the prediction of behaviour, indicating that volitional self-efficacy is only beneficial for individuals with high levels of intentions. Conclusions: The results provide evidence for the phase-specific distinction of self-efficacy in the context of dietary change in an overweight or obese sample. Thus, differentiating between motivational and volitional self-efficacy beliefs should be considered when developing future interventions of dietary change.
\end{abstract}

Keywords: diet, health action process approach, health behaviour change, overweight, phase-specific self-efficacy

\footnotetext{
* Address for correspondence: Sibylle Ochsner, University of Zurich, Department of Psychology, Social and Health Psychology, Binzmuehlestr. 14 / Box 14, CH-8050 Zürich, Switzerland. Email: sibylle.ochsner@psychologie.uzh.ch
} 


\section{INTRODUCTION}

Food habits have changed over recent decades, resulting in the consumption of more fatty and sugary food, which leads to a higher risk for several diseases (WHO, 2000). However, many people fail to change their nutrition behaviour on a long-term basis (Kumanyika et al., 2000). This study focuses on the processes and factors involved in successful long-term modifications of people's diets in general and on reducing daily fat intake in particular. Reducing caloric intake by following a low-fat diet leads to better satiety, palatability and more weight loss compared to following other diets (Astrup, Grunwald, Melanson, Saris, \& Hill, 2000; Shah, McGovern, French, \& Baxter, 1994) and is recommended in order to maintain a lifelong healthy weight (Shick et al., 1998).

\section{Self-Efficacy Beliefs and Nutrition}

Self-efficacy is known to be an important predictor of health behaviour change (Schwarzer, 2008). It originates from Bandura's social-cognitive theory and is defined as the self-confidence in one's own capability to initiate and maintain a new behaviour even if obstacles emerge (Bandura, 1997). Research on self-efficacy includes the investigation of health behaviours such as dietary behaviour, physical exercise, or breast self-examination. In these behaviours, high self-efficacy has been shown to facilitate the adoption and maintenance of the behaviour (Schwarzer, 2008).

In the context of nutrition behaviour, self-efficacy has proved to be an important factor and is examined in most studies (e.g. Contento, Randell, \& Basch, 2002). Research has demonstrated that individuals with higher nutrition self-efficacy are more likely to act on their intentions and translate plans into action (Guiterrez-Dona, Lippke, Renner, Kwon, \& Schwarzer, 2009; Richert et al., 2010). Self-efficacy seems to be a core factor for the initiation and maintenance of dietary behaviour (Richert et al., 2010) and people with higher nutrition-specific self-efficacy are more successful in changing their nutrition in comparison to people with a lower nutrition-specific self-efficacy (Schwarzer, 2008).

\section{Phase-Specific Self-Efficacy Beliefs}

Among theories of health behaviour change, the health action process approach (HAPA; Schwarzer, 2008) places special emphasis on self-efficacy beliefs. The HAPA model distinguishes between a motivational and a volitional phase. In the motivational phase, risk awareness, outcome expectancies, and self-efficacy are predictors of intention. The volitional phase follows intention formation, in which intention, action control, planning, and self- 
efficacy are specified as predictors of behaviour. Self-efficacy has been shown to be beneficial in both phases, namely in the formation of intentions, the initiation and maintenance of behaviour, and the recovery after a lapse (Schwarzer, 2008).

According to the HAPA model, self-efficacy can be differentiated as motivational self-efficacy, which works as one of the predictors of intention formation in the motivational phase, and volition self-efficacy which works as predictor of behaviour in the volitional phase (Schwarzer \& Luszczynska, 2008). This concept of phase-specific self-efficacies has been used in the domain of addictive behaviours (Marlatt, Baer, \& Quigley, 1995). The distinction was developed due to the assumptions that people have to succeed in different tasks during behaviour change, and different phase-specific selfefficacies support these tasks.

Motivational and volitional self-efficacies have recently been investigated but are defined and labelled differently by various authors. In the current study, the terms motivational and volitional self-efficacy are used according to the phases of the HAPA model. Motivational self-efficacy refers to overall confidence to perform a behaviour. In this first phase the individual has not acted yet, but is about to form an intention to do so. High motivational self-efficacy is associated with the development of the intention to change a behaviour (e.g. Luszczynska \& Schwarzer, 2003; Renner, Spivak, Kwon, \& Schwarzer, 2007; Scholz, Sniehotta, \& Schwarzer, 2005; Schwarzer et al., 2007). Volitional self-efficacy refers to beliefs about one's ability to maintain behaviour over a longer time even if obstacles emerge. Therefore it is assumed to be relevant when intentions are high and hence indicative of the volitional phase (e.g. Luszczynska \& Schwarzer, 2003; Renner et al., 2007; Scholz et al., 2005).

In the domain of nutrition behaviour there are only a few studies that have considered phase-specific self-efficacies (Renner et al., 2008; Schwarzer \& Luszczynska, 2008; Schwarzer \& Renner, 2000; Schwarzer et al., 2007). They assessed different behavioural outcomes such as low-fat diet, high-fat food consumption, fruit and vegetable consumption, or a diet rich in vitamins, but they have major similarities: all studies were based on the HAPA model as theoretical background, and assessed factors to do with the motivational phase (risk awareness, outcome expectancies, motivational self-efficacy, behavioural intentions) at baseline and factors to do with the volitional phase (volitional self-efficacy, planning, behaviour) four weeks to six months later. These studies found evidence for the effectiveness of motivational and volitional self-efficacy in the domain of nutrition behaviour: motivational selfefficacy was associated with intentions whereas volitional self-efficacy was associated with nutrition behaviour. However, these associations were assessed cross-sectionally, testing the association between motivational selfefficacy and behavioural intentions as well as volitional self-efficacy and 
behaviour at the same point of measurement (Renner et al., 2008; Schwarzer \& Luszczynska, 2008; Schwarzer \& Renner, 2000; Schwarzer et al., 2007). Thus, it remains unclear whether or not these associations hold across a temporal sequence, that is when the two phase-specific self-efficacy beliefs are assessed at an earlier point in time and the outcomes at a later point in time.

Moreover, none of the four studies concerning nutrition behaviour tested the predictive power of the different phase-specific self-efficacies in competition with each other and therefore no conclusions can yet be drawn about the unique predictive power of phase-specific self-efficacy beliefs. It is assumed that phase-specific self-efficacies demonstrate their relevance in the corresponding phase and are quite ineffective in other phases in the process of behaviour change. This assumption can be tested by moderator analyses with phase indicators as moderator variables, which was done in studies concerning physical exercise (Scholz et al., 2005) and pelvic-floor exercise after prostatectomy (Burkert, Knoll, Scholz, Roigas, \& Gralla, 2012). Scholz and colleagues (2005) demonstrated that the association between volitional selfefficacy (in this case called maintenance self-efficacy) and behaviour was moderated by past behaviour as an indicator of being in the maintenance phase of behaviour change. Individuals who had already started the behaviour before and were therefore maintaining the behaviour benefited more from volitional self-efficacy than those who had not already started (Scholz et al., 2005). Moreover, having a relapse in carrying out a new behaviour moderated the association between recovery self-efficacy (meaning the belief about one's capability to return to the intended behaviour after a lapse) and behaviour. For individuals who experienced a relapse, recovery self-efficacy was beneficial, but it had no effect for individuals who conducted the behaviour without relapse (Burkert et al., 2012; Scholz et al., 2005). The terms maintenance or recovery self-efficacy are used to specify in more detail which of these two facets of volitional self-efficacy is salient in the process of behaviour change. Maintenance self-efficacy refers to the maintenance of a behaviour over a longer time whereas recovery self-efficacy is beneficial after a lapse or relapse.

While some studies (e.g. Scholz et al., 2005) and models (e.g. the Transtheoretical model; Prochaska \& Velicer, 1997) use past behaviour as phase indicator, other approaches use intention as phase indicator (cf. the HAPA model; Schwarzer, 2008; the model of action phases by Heckhausen, 1977). Past behaviour and behavioural intentions differ in their functions: while past behaviour is used to indicate allocation to the maintenance phase in behaviour change (e.g. Scholz et al., 2005), intentions are used to differentiate between allocation to the motivational or volitional phase. The latter approach was applied in the present study in which behavioural intentions are tested as moderator of the association between volitional self-efficacy and behaviour. 
High behavioural intentions refer to the volitional phase in which volitional self-efficacy is expected to be related to behaviour, whereas low behavioural intentions refer to the motivational phase, in which volitional selfefficacy is expected to be ineffective. Testing behavioural intentions as moderator has not been done before and will enhance our knowledge about the combination of volitional self-efficacy and behavioural intentions in the process of behaviour change.

\section{Aims of the Current Study}

The current study ties in with the described studies concerning nutrition behaviour. To the best of our knowledge, no previous study has tested the roles of phase-specific self-efficacy beliefs in predicting behavioural intentions and behaviour at a later time in the domain of nutrition behaviour with overweight or obese individuals. Moreover, we explored whether the association between phase-specific self-efficacies and phase-specific outcomes are moderated by a phase indicator (i.e. behavioural intention). Our assumptions are:

1. Motivational self-efficacy is a stronger predictor of behavioural intentions six months later than volitional self-efficacy, controlling for the effects of the HAPA variables risk perception and outcome expectancies.

2. Volitional self-efficacy is a stronger predictor of low-fat dietary intake six months later compared to motivational self-efficacy, controlling for the effects of the HAPA variables action planning, action control, and behavioural intentions.

3. Behavioural intentions moderate the association between volitional self-efficacy and low-fat dietary intake six months later.

\section{METHOD}

\section{Sample and Procedure}

Data for this longitudinal study were collected within a randomised controlled trial which aimed at changing dietary intake in overweight and obese individuals (Scholz, Ochsner, \& Luszczynska, in press). The sample was recruited via newspaper advertisements and web pages. Inclusion criteria were: Being 18 years or older, overweight or obese (Body mass index, BMI, > 25), with sufficient knowledge of the German language, and no current participation in a professional weight-loss programme.

Participants were randomly allocated to the control group or one of four intervention groups. The baseline assessment (T1) took place at the labora- 
tory of the Department of Psychology at the University of Zurich. Participants received information about the study and the procedure, and signed an informed consent form. Next, participants were given an information sheet about a healthy and low-fat diet based on the guidelines of the Swiss Society of Nutrition and they completed a questionnaire.

Participants in the control group completed the baseline assessment as described above but did not receive any further treatment. Respondents assigned to one of the four intervention groups also took part in different planning interventions: a single planning group, and three groups with three, six, or nine weeks' repeated planning interventions (for a detailed description of the different planning interventions as well as the results of the RCT please see Scholz et al., in press).

Six months after baseline, the follow-up questionnaire (T2) was sent to the participants of all groups by mail together with a prepaid return envelope. Participants who completed the study received 50 CHF. All participants were treated in accordance with the ethical guidelines of the Helsinki Declaration 2000.

The sample consisted of 373 participants, including control and all intervention groups. Of these 373 participants, 72.4 per cent $(n=270)$ were women and the mean age was $52.42(S D=12.79)$ with a range from 18 to 82 years. The majority of the participants were married or in a committed relationship $(n=247,66.2 \%), 15.5$ per cent $(n=58)$ were divorced, 13.7 per cent $(n=58)$ were single, 4.3 per cent $(n=16)$ were widowed, and one person $(0.3 \%)$ did not report his/her marital status. The majority of participants $(n=261,70 \%)$ had children. Most participants were currently employed $(n=226,60.6 \%)$ and had attended nine years of schooling $(n=231,61.9 \%)$. The average BMI was $M=31.05(S D=4.41)$.

Of the initial 373 participants, $274(73.5 \%)$ completed the questionnaire six months later. No significant differences emerged between dropouts and participants who completed both questionnaires with regard to motivational self-efficacy, volitional self-efficacy, behavioural intentions, low-fat dietary intake, outcome expectancies, action planning, and action control. Among socio-demographic and control variables no significant differences emerged for sex, having children, education, social desirability, and being in the control or in one of the intervention groups.

However, systematic dropout emerged for risk awareness $(F(1,369)$ $=10.49, p=.001)$ which was higher in dropouts $(M=4.48, S D=1.28)$ than in continuers $(M=4.00, S D=1.26)$. In terms of socio-demographic variables, significant differences emerged for age $(M=48.57, S D=13.58$ for dropouts, $M=53.82, S D=12.23$ for continuers, $F(1,371)=12.64, p=.000)$ and BMI ( $M=32.13, S D=5.18$ for dropouts, $M=30.67, S D=4.04$ for continuers, $F(1,368)=8.15, p=.005)$. Divorced participants and housewives were more likely to drop out, whereas married and retired participants were more likely 
to continue $\left(\chi^{2}(3)=8.29, p=.040\right.$ for marital status, $\chi^{2}(4)=10.84, p=.028$ for employment).

\section{Measures}

Measures of all constructs and socio-demographic variables were assessed at time 1. At time 2, behavioural intentions and low-fat dietary intake were assessed. Unless otherwise stated, the response format was a 6-point Likert scale ranging from $1=$ completely disagree to $6=$ completely agree. Means, standard deviations, and Cronbach's alphas are reported in Table 1. The following item examples are translated from German.

Motivational self-efficacy was assessed by three items which were adapted from Scholz and colleagues (2005), for example "I am confident that I can change my dietary habits" (see Table 2).

Volitional self-efficacy was measured with four items adapted from Scholz and colleagues (2005), for example "I am confident that I can maintain a low-fat diet on a long-term basis even if I cannot see any positive changes immediately" (see Table 2).

Behavioural intentions were assessed with six items adapted from Scholz, Nagy, Göhner, Luszczynska, and Kliegel (2009), for example "I intend to eat a low-fat diet (e.g. low-fat meat, low-fat cheese, etc.)."

Low-fat dietary intake was measured with a food frequency questionnaire assessing the frequency of intake of low-fat food during the past four weeks (adapted from Renner, Hahn, \& Schwarzer, 1996). After the item stem "During the past four weeks how often did you eat ...", seven items regarding low-fat food, for example "low-fat milk or low-fat dairy products?" followed. The response format ranged from $0=$ never to $6=$ several times a day.

Risk awareness was measured with four items (Scholz et al., 2009), for example "If I keep my lifestyle the way it is, there is a high likelihood that I will develop severe health problems."

Outcome expectancies consist of five items adapted from Scholz et al. (2009), for example "If I eat a low-fat diet, then I can lose weight."

Action Planning was measured with four items (Scholz et al., 2009), for example "I have made a detailed plan regarding when (at what meal) to change my eating habits."

Action control was assessed with nine items (Scholz et al., 2009). The items were introduced by the stem "During the past four weeks ...", and followed by items such as "I closely monitored my eating behaviour", "My intentions to change my eating habits were often on my mind", or "I tried my best to act in accordance with my intentions."

Social desirability was assessed as a control variable. Sixteen items from the social desirability scale (SDS-17) were used (Stöber \& Luther, 2001). The 
106

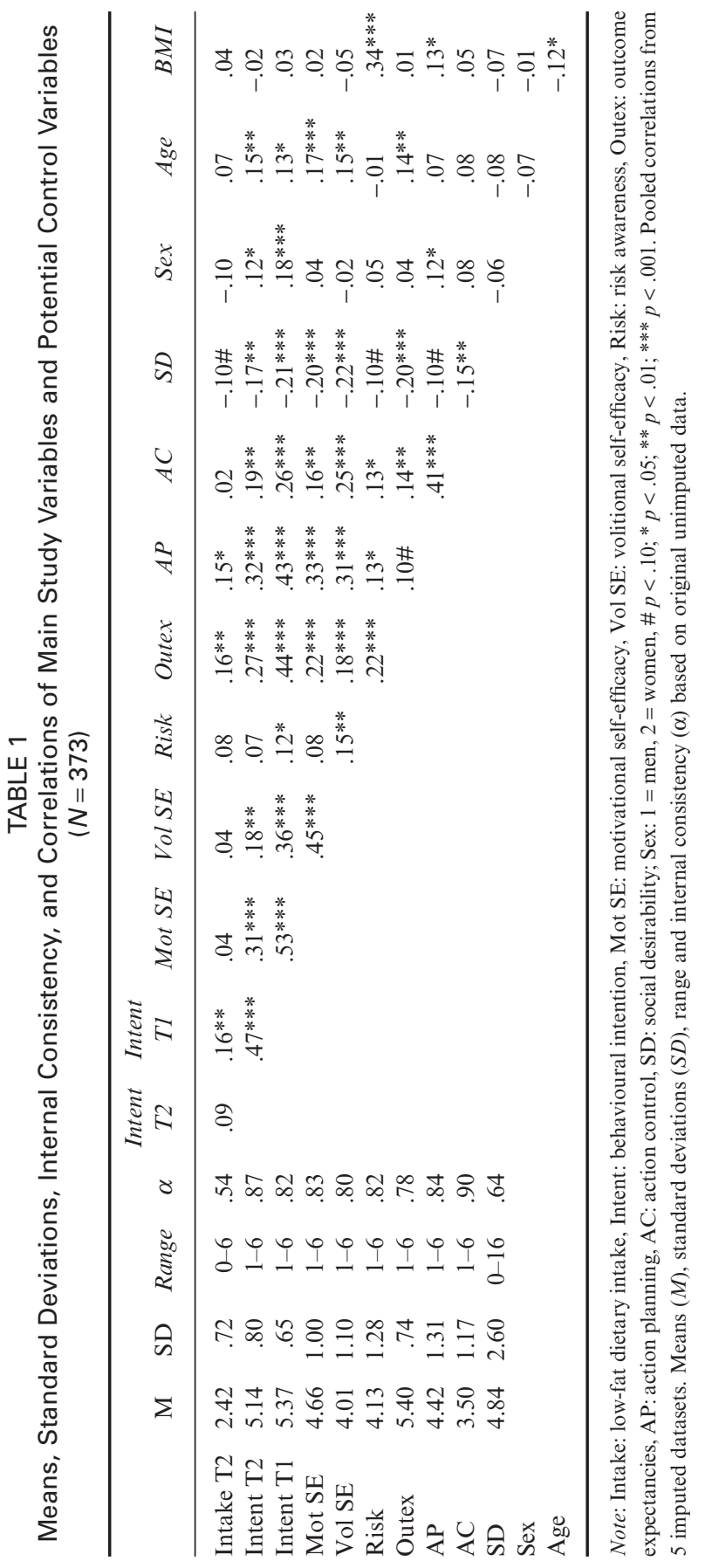


TABLE 2

Pattern Matrix of the Factor Structure of Phase-Specific Self-Efficacy Beliefs using Principal Component Analysis with Varimax Rotation

\begin{tabular}{|c|c|c|}
\hline Items & Factor 1 & Factor 2 \\
\hline I am confident that I can change my dietary habits. & .27 & .82 \\
\hline I am confident that I can eat healthily most of the time. & .07 & .84 \\
\hline I am confident that I can manage to keep a balanced diet. & .25 & .85 \\
\hline $\begin{array}{l}\text { I am confident that I can maintain a low-fat diet on a long-term basis } \\
\text { even if I cannot see any positive changes immediately. }\end{array}$ & .69 & .39 \\
\hline $\begin{array}{l}\text { I am confident that I can maintain a low-fat diet on a long-term basis } \\
\text { even if I am together with friends and relatives who do not keep a } \\
\text { low-fat diet. }\end{array}$ & .77 & .23 \\
\hline $\begin{array}{l}\text { I am confident that I can maintain a low-fat diet on a long-term basis } \\
\text { even if I feel like eating something else. }\end{array}$ & .82 & .09 \\
\hline $\begin{array}{l}\text { I am confident that I can maintain a low-fat diet on a long-term basis } \\
\text { even if I do not feel well. }\end{array}$ & .79 & .12 \\
\hline
\end{tabular}

Note: Primary factor loadings are shown in bold. Factor $1=$ volitional self-efficacy, Factor $2=$ motivational self-efficacy. Based on original unimputed data.

response format was dichotomous, with $1=$ do not agree versus $2=$ agree, higher values indicating higher social desirability.

Dummy variables of the intervention groups were composed as participants were part of a randomised controlled trial (further details on the intervention study are described in Scholz et al., in press) to control for the intervention factors.

\section{Data Analyses}

Dropout analyses have shown that the missing pattern was missing at random (MAR) meaning that the probability of missing values depends on the observed values. Therefore, the dropouts could not be treated as a random subsample of the study sample and could not be completely deleted. Instead, the Multiple Imputation method (MI) was used to account for missing data (Graham, 2009). Multiple Imputation is a Monte Carlo technique that replaces each missing value with a list of several simulated values in the form of generating multiple datasets. Each dataset is analysed separately and results are combined to obtain overall estimates and standard errors. Compared to single imputation methods, Multiple Imputation has the advantage of reflecting the missing data uncertainty (Graham, 2009). For the present study, five databases were generated and analysed. Univariate and multivariate outliers were treated in accordance with Tabachnick and Fidell (2001). All analyses were conducted with SPSS 20. Principal component 
analyses with varimax rotation were computed to test whether the phasespecific distinction of self-efficacy was of sufficient discriminat validity. The extraction criterion was Eigenvalue $>1$ (Tabachnick \& Fidell, 2001). The main analyses were multiple regression analyses to test the unique predictive validity of phase-specific self-efficacy beliefs as competing predictors and a hierarchical regression analysis was performed to test for moderation. For the prediction of behavioural intentions and low-fat dietary intake at $\mathrm{T} 2$, the control variables (social desirability, age, sex, dummy variables of the intervention groups), phase-specific self-efficacy beliefs, and phase-specific socialcognitive variables as specified in the HAPA model at $\mathrm{T} 1$ served as predictors. In the moderation model, control variables were entered first. In a second step behavioural intentions, action planning, action control, self-efficacy beliefs, and the respective moderator were entered followed by the interaction terms in the final step. To avoid problems with multicollinearity, the variables that built the interaction term were mean-centred (Cohen, Cohen, West, \& Aiken, 2003). Simple slope analyses were run to display and test the interaction effects (Preacher, Curran, \& Bauer, 2006).

\section{RESULTS}

\section{Descriptive Statistics}

To test the factorial validity of the phase-specific self-efficacy beliefs, a principal component analysis with varimax rotation was conducted (see Table 2). All items of motivational and volitional self-efficacy at T1 were entered. The analysis resulted in a two-factor solution: volitional self-efficacy consisted as expected of four items with an Eigenvalue of 3.52 and accounted for 50.33 per cent of total variance, motivational self-efficacy consisted as expected of three items with an Eigenvalue of 1.31 and accounted for 18.74 per cent of variance. Thus, principal component analysis confirmed the distinction of the phase-specific self-efficacy beliefs.

Correlations of motivational and volitional self-efficacy, the HAPA variables, low-fat dietary intake, and potential control variables are displayed in Table 1. Motivational and volitional self-efficacy were moderately correlated. All HAPA variables were correlated in a positive association with behavioural intention at $\mathrm{T} 1$ and $\mathrm{T} 2$, except for risk awareness, which was not correlated significantly with behavioural intentions at T2. Outcome expectancies, action planning, and behavioural intentions at $\mathrm{T} 1$ were also positively correlated with low-fat dietary intake at T2. From the potential control variables, BMI was the only one not significantly correlated with the outcomes behavioural intentions and low-fat dietary intake and therefore BMI was not included in the analyses, whereas social desirability, sex, age, and the dummy variables were included as control variables. The correlations from 
sex and age showed that women reported higher behavioural intentions at T1 and $\mathrm{T} 2$ as well as higher action planning, and that increasing age was related to higher reports of intention at T1 and T2, motivational and volitional self-efficacy, and outcome expectancies.

\section{Prediction of Behavioural Intentions at T2}

For the prediction of behavioural intentions at T2, a multiple regression analysis was conducted including control variables, phase-specific selfefficacy beliefs, risk awareness, and outcome expectancies as predictors. As shown in Table 3, motivational self-efficacy strongly predicted behavioural intentions whereas volitional self-efficacy did not emerge as a predictor. Outcome expectancies also predicted behavioural intentions as expected according to the HAPA model but risk awareness did not. In terms of the control variables, one of the dummy variables to control for intervention and

TABLE 3

Prediction of Behavioural Intentions at T2 and Low-Fat Dietary Intake at T2

\begin{tabular}{|c|c|c|c|c|}
\hline \multirow[b]{3}{*}{ Predictor } & \multicolumn{4}{|c|}{ Dependent variables } \\
\hline & \multicolumn{2}{|c|}{$\begin{array}{l}\text { Behavioural } \\
\text { intentions } T 2\end{array}$} & \multicolumn{2}{|c|}{$\begin{array}{l}\text { Low-fat dietary } \\
\text { intake T2 }\end{array}$} \\
\hline & $\mathrm{b}$ & $\mathrm{SE} b$ & $\mathrm{~b}$ & $\mathrm{SE} \mathrm{b}$ \\
\hline Social Desirability & -.02 & .02 & -.03 & .02 \\
\hline Age & .01 & .00 & .00 & .00 \\
\hline Sex & $.18 \#$ & .10 & $-.22 *$ & .10 \\
\hline Dummy variable 1 & .01 & .13 & .20 & .14 \\
\hline Dummy variable 2 & .05 & .14 & .15 & .14 \\
\hline Dummy variable 3 & .09 & .16 & .15 & .13 \\
\hline Dummy variable 4 & $.35^{*}$ & .15 & .03 & .14 \\
\hline Motivational self-efficacy & $.19 * * *$ & .05 & -.07 & .06 \\
\hline Volitional self-efficacy & .02 & .05 & -.03 & .05 \\
\hline Risk awareness & .00 & .04 & & \\
\hline Outcome expectancies & $.21 * *$ & .07 & & \\
\hline Action planning & & & $.08 \#$ & .04 \\
\hline Action control & & & -.03 & .04 \\
\hline Intention at $\mathrm{T} 1$ & & & $.18^{*}$ & .09 \\
\hline$R^{2}$ total & $.17-.22$ & & .08 & \\
\hline
\end{tabular}

Note: Sex: 1 = men, 2 = women; $\# p<.10 ; * p<.05 ; * * p<.01 ; * * * p<.001$. Findings are based on 5 imputed datasets. Due to multiple imputation, unstandardised coefficients and ranges of $R^{2}$ are reported. Prediction of behavioural intentions at T2: $F(11,361)=6.53-9.41^{* * *}$. Prediction of low-fat dietary intake at T2: $F(12,261)=1.80-1.83^{*}$ 
sex showed an effect, indicating that participants of the nine-week planning intervention group as well as women reported higher behavioural intentions.

\section{Prediction of Low-Fat Dietary Intake at T2}

Control variables, phase-specific self-efficacy beliefs, and the HAPA variables action planning, action control, and behavioural intentions were entered in a multiple regression model to predict low-fat dietary intake at T2 (see Table 3). As expected, motivational self-efficacy did not emerge as predictor, but neither did volitional self-efficacy predict low-fat dietary intake. In line with the assumptions of the HAPA model, behavioural intentions at T1 and action planning emerged as predictors but, unexpectedly, action control did not. In terms of the control variables, sex was the only significant predictor showing that men reported higher low-fat dietary intake than women.

\section{Phase Indicators as Potential Moderators}

To test whether behavioural intentions at $\mathrm{T} 1$ as an indicator of being in the motivational or volitional phase moderated the relationship between volitional self-efficacy at T1 and low-fat dietary intake at T2, a hierarchical regression analysis was conducted (see Table 4). In a first step, the control variables were entered, followed by phase-specific self-efficacies, the moderator behavioural intentions, risk awareness, and outcome expectancies in a second step, and finally in a third step the interaction terms. In the last step, action planning, sex, and one of the dummy variables emerged as predictors, indicating that men and participants in the single planning intervention group reported higher low-fat dietary intake. Volitional self-efficacy was not able to explain variance in low-fat dietary intake at $\mathrm{T} 2$, but behavioural intentions emerged as a predictor. Moreover, the interaction between volitional self-efficacy and behavioural intentions was significant, whereas the interaction between motivational self-efficacy and behavioural intention was not. As displayed in Figure 1, for individuals with low behavioural intentions at $\mathrm{T} 1$, which indicates being in the motivational phase, only a low positive association between volitional self-efficacy and behaviour emerged. However, for individuals with high behavioural intentions at T1, which indicates being in the volitional phase, the low-fat dietary intake at $\mathrm{T} 2$ was quite strongly positively associated with volitional self-efficacy at $\mathrm{T} 1$ : the higher the volitional self-efficacy reported, the higher the low-fat dietary intake. Simple slope analysis confirmed that the association between volitional self-efficacy and low-fat dietary intake was significant for individuals with higher behavioural intentions $(t=3.01, p=.003)$ and with a smaller effect also for individuals with lower behavioural intentions $(t=2.09, p=.038)$. 
TABLE 4

Moderation Analysis of Volitional Self-Efficacy at T1 by Level of Behavioural Intention at T1 Predicting Low-Fat Dietary Intake Six Months Later (T2)

\begin{tabular}{|c|c|c|c|c|c|c|}
\hline \multirow[b]{2}{*}{ Predictor } & \multicolumn{2}{|c|}{ Step 1} & \multicolumn{2}{|c|}{ Step 2} & \multicolumn{2}{|c|}{ Step 3} \\
\hline & $\mathrm{b}$ & $\mathrm{SE} \mathrm{b}$ & $\mathrm{b}$ & $\mathrm{SE} \mathrm{b}$ & $\mathrm{b}$ & $\mathrm{SE} \mathrm{b}$ \\
\hline SD & $-.03 \#$ & .02 & -.03 & .02 & -.02 & .02 \\
\hline Age & .00 & .00 & .00 & .00 & .00 & .00 \\
\hline Sex & $-.17 \#$ & .10 & $-.22 *$ & .10 & $-.20^{*}$ & .10 \\
\hline Dummy 1 & .21 & .14 & .20 & .14 & $.24 \#$ & .14 \\
\hline Dummy 2 & .16 & .14 & .15 & .14 & .17 & .14 \\
\hline Dummy 3 & .15 & .13 & .15 & .13 & .17 & .13 \\
\hline Dummy 4 & .04 & .14 & .03 & .14 & .03 & .14 \\
\hline Mot SE & & & -.07 & .06 & -.09 & .06 \\
\hline Vol SE & & & -.03 & .05 & -.02 & .05 \\
\hline Intent $\mathrm{T} 1$ & & & $.18 *$ & .09 & $.20 \#$ & .10 \\
\hline $\mathrm{AP}$ & & & $.07 \#$ & .04 & $.07 \#$ & .04 \\
\hline $\mathrm{AC}$ & & & -.03 & .04 & -.03 & .04 \\
\hline Mot SE*intent & & & & & -.08 & .06 \\
\hline Vol SE*intent & & & & & $.18 * *$ & .06 \\
\hline$\Delta R^{2}$ & & & $.04 *$ & & $.03 * *$ & \\
\hline$R^{2}$ total & .04 & & .08 & & .11 & \\
\hline
\end{tabular}

Note: SD: social desirability, mot SE: motivational self-efficacy, vol SE: volitional self-efficacy, intent T1: behavioural intentions at T1, AP: action planning, AC: action control, Sex: $1=$ men, $2=$ women; $\# p<.10$; ${ }^{*} p<.05 ;{ }^{* *} p<.01 ; * * * p<.001$. Findings are based on 5 imputed datasets. Due to multiple imputation, unstandardised coefficients are reported. Prediction of low-fat dietary intake at T2: Step 1: $F(7,266)=1.45$, Step 2: $F(5,261)=.23-2.31^{*}$, Step 3: $F(2,259)=4.93-5.05^{* *}$.

\section{DISCUSSION}

The current study tested the distinction of phase-specific self-efficacies and their relative importance in dietary intention formation and behaviour. Moreover, we explored whether a phase indicator moderated the association between phase-specific self-efficacies and phase-specific outcomes.

In line with the assumptions of the HAPA model and with prior findings (Burkert et al., 2012; Scholz et al., 2005), principal component analysis confirmed the distinction of the phase-specific self-efficacy beliefs. In predicting behavioural intentions, motivational self-efficacy emerged as a strong predictor whereas volitional self-efficacy was not significantly associated with intentions. Since prior studies (e.g. on physical exercise, Renner et al., 2007; Schwarzer et al., 2007; breast-self examination, Luszczynska \& Schwarzer, 2003; or dental flossing, Schwarzer et al., 2007) assessed motivational selfefficacy and intentions at the same time or could not demonstrate a significant association across time (Burkert et al., 2012), the current study is the first to demonstrate the unique predictive validity of motivational self-efficacy to 


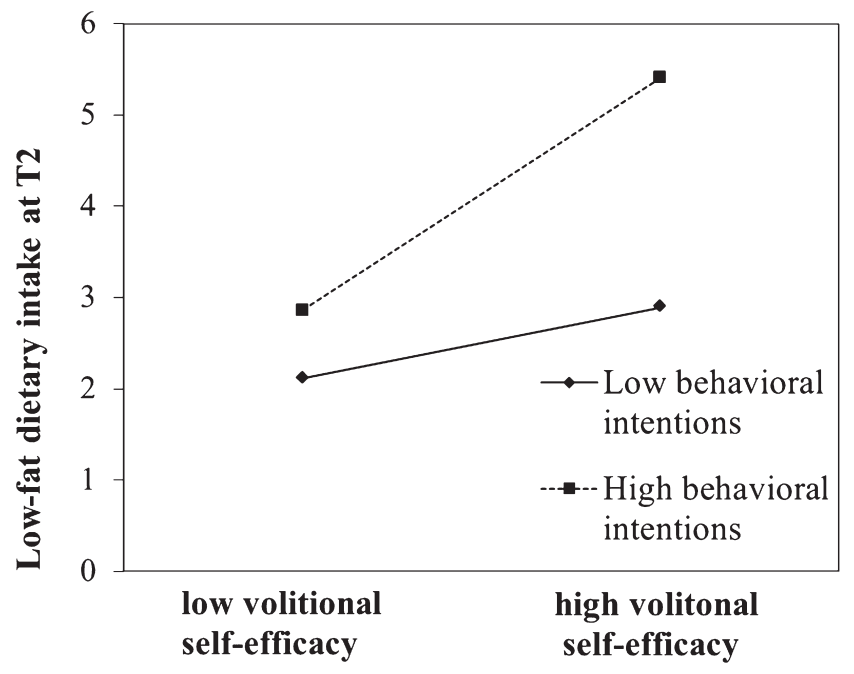

FIGURE 1. Interaction of volitional self-efficacy and behavioural intentions on low-fat dietary intake at T2.

predict behavioural intentions at a later time. As expected, outcome expectancies were also significantly associated with behavioural intentions but risk awareness was not. This is in line with studies on dental flossing, seat belt use (Schwarzer et al., 2007), or smoking in young adults (Schwarzer \& Luszczynska, 2008). Likewise, in a study on nutrition behaviour, risk awareness was the weakest predictor of behavioural intentions compared to self-efficacy and outcome expectancies (Schwarzer \& Renner, 2000). As risk awareness is assumed to be the starting point of a deliberative process, it might well be that in a sample with rather strong motivation to change behaviour, as was the case in the present study, risk awareness loses its influence. Moreover, the scale correspondence between risk perception and behavioural intentions was low according to the principles of compatibility (Ajzen, 1988), as risk perception referred to a healthy lifestyle in general whereas behavioural intentions referred to low-fat dietary intake as a particular health behaviour. Higher correspondence might have resulted in higher associations.

In predicting low-fat dietary intake six months later, behavioural intentions and action planning emerged as significant predictors, in line with the assumptions of the HAPA model but unexpectedly action control did not. Action plans are formed before the situation comes about, whereas action control is needed during the behaviour. For the current study's participants, the prospective strategy seemed to be more successful than concurrent selfregulation. In a difficult nutrition situation, such as eating in a restaurant, it 
might be easier to plan ahead which menu to choose rather than evaluate the menu and eventually stop eating once it is on the plate. The importance of forming action plans and memorising them in critical situations seems to be crucial especially in complex and repetitive behaviours such as nutrition behaviour (e.g. Wiedemann, Lippke, Reuter, Ziegelmann, \& Schüz, 2011; Wiedemann, Lippke, \& Schwarzer, 2012).

Contrary to our assumptions, volitional self-efficacy did not predict lowfat dietary intake six months later. Prior studies have demonstrated an association between volitional self-efficacy and behaviour assessed at the same time (e.g. Luszczynska \& Schwarzer, 2003; Renner et al., 2007), and a study concerning physical activity confirmed volitional self-efficacy as a unique predictor of behaviour four months later (Scholz et al., 2005). Although no main effect from volitional self-efficacy on dietary intake was found in the present study, behavioural intentions emerged as moderator of the volitional self-efficacy-behaviour relationship. Moreover, in line with our assumptions, the interaction between motivational self-efficacy and behavioural intentions was not significant in predicting behaviour. These findings support the assumptions that volitional self-efficacy is beneficial for individuals in the volitional phase only, whereas it is not effective as a main effect in the whole sample including individuals in the motivational phase. The fact, that the simple slope analysis was significant for individuals with higher behavioural intentions and at a lower level also for individuals with lower behavioural intentions might be seen as a limitation. However, the present study is the first to demonstrate behavioural intentions as moderator-and thus as phase indicator - of the association between volitional self-efficacy and behaviour. In line with prior studies on the moderating effects of phase indicators for the relationship of phase-specific self-efficacies and phase-specific outcomes (Burkert et al., 2012; Scholz et al., 2005), these findings confirm that phasespecific self-efficacies unfold their unique relevance only in the corresponding phase.

The theoretical question remains about which of the two interacting variables (volitional self-efficacy and behavioural intentions) is seen as the moderator. Applying a social-cognitive theory perspective (Bandura, 1997) might also justify considering self-efficacy to be the moderator. In the present study, however, behavioural intentions were considered the indicator of belonging to the motivational or volitional phase in the behaviour change process. Thus, intentions were specified as the moderator.

The present study has several limitations. First, dietary behaviour was assessed by self-reports. This might put in question the validity of the assessment since the reported amount of food may not be recalled accurately over longer periods. However, objective assessment methods of dietary intake have disadvantages too, such as causing reactive changes in nutrition behaviour, whereas food frequency questionnaires do not cause alterations in 
consumption because they are completed in retrospect. Moreover, food frequency questionnaires are especially suitable for assessing particular foods or food groups (Wolper, Heshka, \& Heymsfield, 1995), as was done in the present study. Also, social desirability was controlled for to account for potential bias. Another limitation was the systematic drop-out of participants, but this was accounted for by multiple imputation (Graham, 2009).

Finally, it can be argued that in the moderator analysis the phase allocator, behavioural intentions, is a continuous measure. Measuring an individual's position on continuous dimensions, where each dimension should correspond to a different stage, can be considered to be inconsistent with the conceptual perspective of discrete stages (Sutton, 2001). Nonetheless such measures have proved to be useful as was the case in the present study (e.g. De Vet, de Nooijer, de Vries, \& Brug, 2007). On average, the participants had relatively high intentions, therefore it might well be possible that in a sample with a broader range of intentions even stronger associations with intentions might have emerged.

Despite these limitations, the present findings are meaningful. The differentiation between motivational and volitional self-efficacy was supported. Also, results demonstrated that individuals, although being in the same setting such as being overweight and wanting to reduce weight, may be in different stages of behaviour change and therefore need different interventions. For individuals in the motivational phase, interventions should strengthen their belief in being able to start a new health behaviour. Individuals who have already decided to act or have started to act need confidence in their abilities to master the difficulties of behaviour change.

Future studies should further investigate the role of phase-specific selfefficacy beliefs. Profound knowledge about phase-specific self-efficacy beliefs in the process of health behaviour change could improve tailored interventions which should boost people's self-confidence in their own ability to overcome specific obstacles in the process of health behaviour change.

\section{ACKNOWLEDGEMENTS}

This study was funded in part by the "Stiftung Suzanne und Hans Biaesch zur Foerderung der Angewandten Psychologie". We would like to thank all students who helped with data collection. While preparing this manuscript Sibylle Ochsner was funded by the Swiss National Foundation (100014_124516).

\section{REFERENCES}

Ajzen, I. (1988). Attitudes, personality, and behaviour. Homewood, IL: Dorsey Press. Astrup, A., Grunwald, G.K., Melanson, E.L., Saris, W.H., \& Hill, J.O. (2000). The role of low-fat diets in body weight control: A meta-analysis of ad libitum dietary 
intervention studies. International Journal of Obesity and Related Metabolic Disorders: Journal of the International Association for the Study of Obesity, 24, 15451552. doi:10.1038/sj.ijo.0801453

Bandura, A. (1997). Self-efficacy: The exercise of control. New York: Freeman.

Burkert, S., Knoll, N., Scholz, U., Roigas, J., \& Gralla, O. (2012). Self-regulation following prostatectomy: Phase-specific self-efficacy beliefs for pelvic-floor exercise. British Journal of Health Psychology, 17, 273-279. doi:10.1111/j.20448287.2011.02037.x

Cohen, J., Cohen, P., West, S.G., \& Aiken, L.S. (2003). Applied multiple regression/ correlation analysis for the behavioral sciences (3rd edn.). Mahwah, NJ: Lawrence Erlbaum Associates Publishers.

Contento, I.R., Randell, J.S., \& Basch, C.E. (2002). Review and analysis of education measures used in nutrition education intervention research. Journal of Nutrition Education and Behaviour, 34, 2-25. doi:10.1016/S1499-4046(06)60220-0

De Vet, E., de Nooijer, J., de Vries, N.K., \& Brug, J., (2007). Comparing stage of change and behavioural intention to understand fruit intake. Health Education Research, 22, 599-608. doi:10.1093/her/cyl121

Graham, J.W. (2009). Missing data analysis: Making it work in the real world. Annual Review of Psychology, 60, 549-576. doi:10.1146/annurev.psych.58.110405. 085530

Guiterrez-Dona, B., Lippke, S., Renner, B., Kwon, S., \& Schwarzer, R. (2009). Self-efficacy and planning predict dietary behaviours in Costa Rican and South Korean women: Two moderated mediation analyses. Applied Psychology: Health and Well-Being, 1, 91-104. doi:10.1111/j.1758-0854.2008.01001.x

Heckhausen, H. (1977). Achievement motivation and its constructs: A cognitive model. Motivation and Emotion, 1, 283-329. doi:10.1007/BF00992538

Kumanyika, S.K., Van Horn, L., Bowen, D., Perri, M.G., Rolls, B.J., Czajkowski, S.M. et al. (2000). Maintenance of dietary behaviour change. Health Psychology, 19, 42-56. doi:10.1037/0278-6133.19.Suppl1.42

Luszczynska, A., \& Schwarzer, R. (2003). Planning and self-efficacy in the adoption and maintenance of breast self-examination: A longitudinal study on selfregulatory cognitions. Psychology and Health, 18, 93-108. doi:10.1080/0887044021 000019358

Marlatt, G.A., Baer, J.S., \& Quigley, L.A. (1995). Self-efficacy and addictive behaviour. In A. Bandura (Ed.), Self-efficacy in changing societies (pp. 289-315). New York: Cambridge University Press. doi:10.1017/CBO9780511527692.012

Preacher, K.J., Curran, P.J., \& Bauer, D.J. (2006). Computational tools for probing interaction effects in multiple linear regression, multilevel modeling, and latent curve analysis. Journal of Educational and Behavioral Statistics, 31, 437-448. doi:10.3102/10769986031004437

Prochaska, J.O., \& Velicer, W.F. (1997). The transtheoretical model of health behavior change. American Journal of Health Promotion, 12, 38-48. doi:10.4278/08901171-12.1.38

Renner, B., Hahn, A., \& Schwarzer, R. (1996). Dokumentation der Meßinstrumente des Forschungsprojekts "Berlin Risk Appraisal and Health Motivation Study" (BRAHMS). Berlin: Freie Universität Berlin. 
Renner, B., Kwon, S., Yang, B.H., Paik, K.C., Kim, S.H., Roh, S. et al. (2008). Social-cognitive predictors of dietary behaviours in South Korean men and women. International Journal of Behavioral Medicine, 15, 4-13. doi:10.1007/ BF03003068

Renner, B., Spivak, Y., Kwon, S., \& Schwarzer, R. (2007). Does age make a difference? Predicting physical activity of South Koreans. Psychology and Aging, 22, 482-493. doi:10.1037/0882-7974.22.3.482

Richert, J., Reuter, T., Wiedemann, A.U., Lippke, S., Ziegelmann, J., \& Schwarzer, R. (2010). Differential effects of planning and self-efficacy on fruit and vegetable consumption. Appetite, 54, 611-614. doi:10.1016/j.appet.2010.03.006

Scholz, U., Nagy, G., Göhner, W., Luszczynska, A., \& Kliegel, M. (2009). Changes in self-regulatory cognitions as predictors of changes in smoking and nutrition behaviour. Psychology \& Health, 24, 545-561. doi:10.1080/08870440801902519

Scholz, U., Ochsner, S., \& Luszczynska, A. (in press). Comparing different boosters of planning interventions on changes in fat consumption in overweight and obese individuals: A randomized controlled trial. International Journal of Psychology. doi:10.1080/00207594.2012.661061

Scholz, U., Sniehotta, F.F., \& Schwarzer, R. (2005). Predicting physical exercise in cardiac rehabilitation: The role of phase-specific self-efficacy beliefs. Journal of Sport \& Exercise Psychology, 27, 135-151.

Schwarzer, R. (2008). Modeling health behavior change: How to predict and modify the adoption and maintenance of health behaviors. Applied Psychology: An International Review, 57, 1-29. doi:10.1111/j.1464-0597.2007.00325.x

Schwarzer, R., \& Luszczynska, A. (2008). How to overcome health-compromising behaviors. European Psychologist, 14, 141-151. doi:10.1027/1016-9040.13.2.141

Schwarzer, R., \& Renner, B. (2000). Social-cognitive predictors of health behavior: Action self-efficacy and coping self-efficacy. Health Psychology, 19, 487-495. doi:10.1037/0278-6133.19.5.487

Schwarzer, R., Schüz, B., Ziegelmann, J.P., Lippke, S., Luszczynska, A., \& Scholz, U. (2007). Adoption and maintenance of four health behaviors: Theory-guided longitudinal studies on dental flossing, seat belt use, dietary behavior, and physical activity. Annals of Behavioral Medicine, 33, 156-166. doi:10.1007/ BF02879897

Shah, M., McGovern, P., French, S., \& Baxter, J. (1994). Comparison of a low-fat, ad libitum complex-carbohydrate diet with a low-energy diet in moderately obese women. American Journal of Clinical Nutrition, 59, 980-984.

Shick, S.M., Wing, R.R., Klem, M.L., McGuire, M.T., Hill, J.O., \& Seagle, H. (1998). Persons successful at long-term weight loss and maintenance continue to consume a low-energy, low-fat diet. Journal of the American Dietetic Association, 98, 408413. doi:10.1016/S0002-8223(98)00093-5

Stöber, J., \& Luther, M. (2001). The social desirability scale-17 (SDS-17): Convergent validity, discriminant validity, and relationship with age. European Journal of Psychological Assessment, 17, 222-232. doi:10.1027//1015-5759.17.3.222

Sutton, S. (2001). Back to the drawing board? A review of applications of the transtheoretical model to substance use. Addiction, 96, 175-186. doi:10.1080/ 09652140020017049 
Tabachnick, B.G., \& Fidell, L.S. (2001). Using multivariate statistics (4th edn.). Boston, MA: Allyn and Bacon.

Wiedemann, A.U., Lippke, S., Reuter, T., Ziegelmann, J.P., \& Schüz, B. (2011). The more the better? The number of plans predicts health behaviour change. Applied Psychology: Health and Well-Being, 3, 87-106. doi:10.1111/j.1758-0854.2010. 01042.x

Wiedemann, A.U., Lippke, S., \& Schwarzer, R. (2012). Multiple plans and memory performance: Results of a randomized controlled trial targeting fruit and vegetable intake. Journal of Behavioural Medicine. Advance online publication. doi:10.1007/ s10865-011-9364-2

Wolper, C., Heshka, S., \& Heymsfield, S.B. (1995). Measuring food intake: An overview. In D.B. Allison (Ed.), Handbook of assessment methods for eating behaviours and weight-related problems (pp. 215-240). London: Sage Publications. doi:10.1080/10640266.2011.584818

World Health Organisation (WHO) (2000). Obesity: Preventing and managing the global epidemic: Report of a WHO consultation. Geneva: WHO. 